\title{
Slow Late Component in Conditioned Stimulus-Evoked Potentials from the Amygdala after Fear Conditioning in the Rat
}

\author{
J.M.J. Knippenberg, E.L.J.M. van Luijtelaar, and J.H.R. Maes \\ University of Nijmegen, Department of Biological Psychology, \\ P.O. Box 9104, 6500 HE Nijmegen, The Netherlands
}

\begin{abstract}
Male Wistar rats were subjected to a differential Pavlovian fear conditioning procedure in which one of two tones $(6$ or $10 \mathrm{kHz})$ was followed by an electric shock $\left(\mathrm{CS}^{+}\right)$and the other was not $\left(\mathrm{CS}^{-}\right)$. Before and after fear conditioning, we recorded the evoked potentials elicited by $\mathrm{CS}^{+}$and $\mathrm{CS}^{-}$from electrodes aimed at the lateral nucleus of the amygdala. Before conditioning, a slow, negative component with peak amplitude around $150 \mathrm{~ms}$ was present in the evoked potentials. This component was sensitive to habituation. After fear conditioning, both $\mathrm{CS}^{+}$and $\mathrm{CS}^{-}$elicited the same late component, albeit with a larger amplitude. This enhancement was temporary: decreasing amplitude was observed in the course of CS test presentations under extinction. Prior research revealed a comparable slow component in the amygdala of the cat under similar experimental conditions. The collective results indicate that the large late component in the amygdala is enhanced by fear conditioning, suggesting that such enhancement reflects the anticipation of a biologically significant event.
\end{abstract}

\footnotetext{
Reprint requests to: Dr. E.L.J.M. van Luijtelaar, University of Nijmegen, Department of Biological Psychology, P.O. Box 9104, 6500 HE Nijmegen, The Netherlands; e-mail: luijtelaar@nici.kun.nl.
}

\section{KEYWORDS}

neurophysiology, electroencephalography, freezing, associative learning, neural plasticity

\section{INTRODUCTION}

Over the past decades, animal studies have outlined the neural circuitry involved in fear conditioning (see LeDoux, 1995, 2000; Maren, 2001, for reviews). Auditory fear conditioning is a form of Pavlovian conditioning in which a tone, the conditioned stimulus (CS), is followed by an electric shock, the unconditioned stimulus (US). After several CS-US pairings, the animal has learned that the presence of the CS predicts the US. This predictive relationship is reflected in the ability of the CS to evoke a conditioned response (CR) like freezing (for example, Fanselow, 1989).

The amygdala is a key structure of the neural circuitry underlying fear conditioning. Sensory information about the CS reaches the amygdala via a direct thalamic and an indirect thalamo-cortical route. Both the thalamic and cortical projections terminate in the lateral nucleus of the amygdala (LA) (LeDoux et al., 1991). From the LA, information is passed to the central nucleus of the amygdala, which in turn sends efferent projections to several hypothalamic and brainstem nuclei that produce the behavioral, physiological, and endocrine responses characteristic of fear (Veening et al., 1984). The thalamic route is believed to perform 
a 'quick and dirty' type of stimulus analysis, whereas the cortical inputs provide the LA with more detailed information about the stimulus at hand. Based on the thalamic inputs, the organism rapidly initiates defensive responses, which can subsequently be continued or ceased when cortical information confirms or disconfirms the presence of threat, respectively.

More recently, neurophysiological studies have examined how fear conditioning affects the processing of the CS by the lateral amygdala (Collins \& Paré, 2000; Hennevin et al., 1998; Maren, 2000; Quirk et al., 1995; Rogan et al., 1997; Tang et al., 2001). Single-cell recording studies of lateral LA neurons found an increase in firing rate to the $\mathrm{CS}$ as a result of auditory fear conditioning (Hennevin et al., 1998; Maren, 2000; Quirk et al., 1995). Evoked potentials (EPs) to the $\mathrm{CS}$, recorded from the lateral nucleus, exhibit an increase in the amplitude of an early negative component as a result of fear conditioning (Collins \& Paré, 2000; Rogan et al., 1997; Tang et al., 2001). This early negative component reflects local rather than volume-conducted activity because the component has a temporal overlap with the unit activity of LA neurons recorded with the same electrode in both the rat (Rogan \& LeDoux, 1995) and the cat (Collins \& Paré, 1999, 2000). Furthermore, the enhancement of this component is believed to reflect an endogenous form of long-term potentiation that underlies fear conditioning, and a step-by-step account of the cellular processes underlying this potentiation has recently been given (Blair et al., 2001).

Far less attention has been given to the late components of EPs elicited by the CS. Using cats as subjects, Collins and Paré recorded certain notable late components in EPs from the LA to the CS after fear conditioning (Collins \& Paré, 2000) and in an anticipatory fear paradigm (Paré \& Collins, 2000). Furthermore, in rats, Kuniecki et al.
(2002) observed a late EP component after fear conditioning in recordings from the central amygdaloid nucleus, which was interpreted in relation to simultaneously recorded decelerations in heart rate.

Given the lack of data on late EP components from the LA in rats, the present study recorded CSelicited EPs from the LA of rats before and after differential auditory fear conditioning. Differential fear conditioning involves the presentation of a tone $\left(\mathrm{CS}^{+}\right)$that is followed by a shock and another tone that is not $\left(\mathrm{CS}^{-}\right)$. Importantly, in the present study, the acoustic frequencies of the $\mathrm{CS}^{+}$and $\mathrm{CS}^{-}$ were counterbalanced, which is crucial in view of robust findings demonstrating differences in EP component amplitudes and in single-cell response amplitudes, as a function of acoustic frequency of the stimulus (for example, Bordi et al., 1993; Collins \& Paré, 2000).

\section{EXPERIMENTAL}

\section{Animals}

Thirteen male Wistar rats, weighing 250 to 280 $\mathrm{g}$ each at the time of surgery, were housed in pairs in standard laboratory cages with ad libitum access to food and water. The rats were maintained on a 12-h light-dark cycle with lights off at $07.00 \mathrm{~h}$; the experiments were conducted during the dark phase of the cycle. All animals were experimentally naive. The animal ethics committee of the University of Nijmegen approved the experimental procedures.

\section{Electrode implantation}

General anesthesia was induced and maintained through the administration of gaseous isofluorane. The head was fixed in a stereotaxic instrument and its position was adjusted until a flat 
skull position was obtained. The rat was placed on a heat pad to prevent hypothermia and an injection of atropine sulfate $(0.1 \mathrm{~mL}, \mathrm{i} . \mathrm{m}$.) was given at the beginning of surgery. The screw of the ground electrode was attached to the skull overlying the cerebellum. More anterior, another screw was fixed to the skull for later attachment of a strip connector. The lateral nucleus of the right LA was located at the following stereotaxic coordinates: anterioposterior $-3.60 \mathrm{~mm}$, mediolateral -5.40 $\mathrm{mm}$, and dorsoventral $-7.80 \mathrm{~mm}$ (Paxinos \& Watson, 1998). A reference electrode was implanted into the cerebellum. After implantation, the electrodes were assembled in the strip connector and the connector was embedded with dental acrylic cement. The skin was sutured and the animal was placed under a heating lamp in its home cage until it awoke from the anesthesia. Animals were housed individually after surgery and given a recovery period of at least 1 week.

\section{Apparatus}

The EEG recording and conditioning took place in an experimental box $(50 \times 25 \times 45 \mathrm{~cm})$ consisting of two compartments. Each compartment had a grid floor made of stainless steel bars. The box was placed inside a cage of Faraday $(110 \times 70$ $\times 130 \mathrm{~cm}$ ), and the rat's behavior could be observed through a window at the back of the cage. A button-box was used to register different behavioral categories simultaneously with the ongoing EEG. Background white noise was presented through a loudspeaker located approximately $80 \mathrm{~cm}$ above the grid floor of the experimental box. The presentation of auditory stimuli was controlled by an AEP Stimulus Generator, which was connected to an audio amplifier. A shock scrambler controlled the delivery of an electric shock through the grid floor of the box and a shock interrupter was used during post-conditioning recording to switch off the ongoing EEG shortly before the delivery of a reinstatement foot shock (see Experimental procedure). Immediately after the shock, the EEG was switched on again and stabilized rapidly. The rat's behavior was recorded during conditioning with a black and white video camera for off-line quantification.

\section{EEG recording}

The rats were connected to a recording cable that can rotate by means of a swivel, allowing the animals to move freely. Signals from the active electrodes were fed into differential amplifiers together with the signal from the reference electrode. A potential difference was measured between the output signal of the differential amplifier and the signal from the ground electrode. The analogue signal was amplified 5000 or 10000 times and band-pass filtered with high-pass and low-pass filters set at 1 and $500 \mathrm{~Hz}$, respectively. The amplified and filtered signal was sampled at $1024 \mathrm{~Hz}$. WinDaq (DATAQ Instruments, Inc.) software was used for data acquisition.

\section{Experimental procedure}

Pre-conditioning. The first phase consisted of a single session. Each rat was placed inside the experimental box and connected to the recording equipment. Background white noise $(70 \mathrm{~dB})$ was used to mask irrelevant laboratory sounds. The rat was first given $30 \mathrm{~min}$ to explore the novel environment, after which the EEG recording was initiated. A $6-\mathrm{kHz}$ tone and a $10-\mathrm{kHz}$ tone were repeatedly presented during the session. Except for acoustic frequency, the tones had the same stimulus parameters: both had a rise and fall time of $10 \mathrm{~ms}$, a 5-s duration, and a loudness of $80 \mathrm{~dB}$. Each tone was presented 200 times; the interstimulus interval varied randomly between 8 and 
$12 \mathrm{~s}$ (average: $10 \mathrm{~s}$ ). The tones were presented in a random order, with the restriction that no more than two consecutive tones had the same frequency. The presentation of all 400 stimuli took about $1 \mathrm{~h}$, after which the rat was disconnected from the recording cable and returned to its home cage.

Conditioning. During the conditioning sessions, (the first was initiated $90 \mathrm{~min}$ after the preconditioning session), 2 rats were placed inside the experimental box, separated from each other by vertical stainless steel bars. Conditioning thus took place in pairs. The rats stayed in the experimental box for $15 \mathrm{~min}$ before the initiation of the conditioning trials. The rats then received a differential tone-conditioning schedule, using the tones from the pre-conditioning session. One tone was paired with a foot shock $\left(\mathrm{CS}^{+}\right)$; the other was not $\left(\mathrm{CS}^{-}\right)$. For Group 1, the $\mathrm{CS}^{+}$was the $6-\mathrm{kHz}$ tone and the $\mathrm{CS}^{-}$was the $10-\mathrm{kHz}$ tone; for Group 2 this relation was reversed. The US, which was presented at $\mathrm{CS}^{+}$termination, had an intensity of $0.5 \mathrm{~mA}$ and a duration of 0.5 -s. A 3-min (range: 2.5 to $3.5 \mathrm{~min}$ ) variable inter-trial interval was used. The presentation of the tones was semi-random: no more than two consecutive tones were of the same frequency. Each conditioning session consisted of $10 \mathrm{CS}^{+}$and $10 \mathrm{CS}^{-}$presentations, with each animal receiving 3 sessions. The interval between the first and second session was $45 \mathrm{~min}$; the interval between the second and third session was $17 \mathrm{~h}$.

Post-conditioning. This phase was identical to the pre-conditioning phase, except for the use of a reinstatement procedure (e.g., Bouton \& Bolles, 1979). Specifically, a single shock was presented after an average of 20 (range: 15 to 25 ) $\mathrm{CS}^{+}$and $\mathrm{CS}^{-}$presentations, with a 3-min mean interval between termination of the CS and onset of the US (range: 2.5 to $3.5 \mathrm{~min}$ ). The purpose of the separate presentations was to counteract extinction, without presenting any novel CS-shock conditioning trials.

\section{Statistical analysis}

Conditioned responding to the $\mathrm{CS}^{+}$and $\mathrm{CS}^{-}$ was indexed by the time (in seconds) that each rat spent freezing during these stimuli. Freezing was defined as the absence of all visible movement, except that required for respiration and a pendulum motion of the head (for example, Maes \& Vossen, 1993). The presentation of a CS was marked by a visual signal on the video images. The mean freezing times to the $\mathrm{CS}^{+}$and $\mathrm{CS}^{-}$were calculated for each session and subjected to a repeated-measures analysis of variance (ANOVA), with Session $(1,2$, or 3$)$ and CS Type $\left(\mathrm{CS}^{+}\right.$or $\left.\mathrm{CS}^{-}\right)$ as within-subject factors, and Group (1 or 2$)$ as a between-subject factor.

Two types of analysis were performed on the electrophysiological data. The first analysis focused on the pre-conditioning EP components as a function of the frequency of the auditory stimulus. This analysis took into account that, in rats, the amplitude of auditory EP components depends on the behavioral and vigilance state of the animal (Meerenet al., 2001). Therefore, the only CSs included into the calculation of EPs were those that had occurred during a neutral behavioral and vigilance state, namely passive wakefulness.

During the EEG recording, a rat's behavior was classified as either active or passive and the behavioral score was registered in a separate channel in Windaq. A CS was included in the analysis if the following two conditions were met - the presence of an EEG characteristic of passive wakefulness and a passive behavioral score. All other CSs were excluded from the analysis. This analysis used only the EP data from the last $30 \mathrm{CS}^{+}$and $\mathrm{CS}^{-}$pre-conditioning trials to preclude any novelty effect that is potentially associated with the initial $\mathrm{CS}^{+}$and the $\mathrm{CS}^{-}$ presentations. 
For the second type of analysis, the pre- and post-conditioning EEG was divided into 4 blocks of $50 \mathrm{CS}^{+} / \mathrm{CS}^{-}$presentations. Only CSs presented during EEG artifacts and spike-wave discharges, a form of epileptic activity found in many rat strains, were removed. All other CSs were included, except those eliciting a distorted EEG response during periods of deep sleep. The analyses performed on these data were repeated measures ANOVAs, with CS Type $\left(\mathrm{CS}^{+}\right.$or $\left.\mathrm{CS}^{-}\right)$, Block (for example, Block 1 or Block 4), or Phase (pre- or post-conditioning) as within-subject factors, and Group (1 or 2) as a between-subject factor.

The latencies of the EP components were corrected for the time-lag for the auditory CS to reach the tympanic membrane. Based on the distance between the loudspeaker and the floor of the experimental box, an air travel time of $3 \mathrm{~ms}$ was calculated and, accordingly, $3 \mathrm{~ms}$ was subtracted from the latencies of all EP components.

\section{Histology}

After the experiment was completed, each rat received an intraperitoneal injection of a high dose of sodium pentobarbital. Once the rat was deeply anesthetized, a small electrolytic lesion was made at the tip of the recording electrode by passing an anodal direct current of $20 \mu \mathrm{A}$ through the electrode for $15 \mathrm{~s}$. The rats were subsequently perfused intracardially with physiological saline followed by a solution of $2 \%$ potassium ferrocyanide in $4 \%$ paraformaldehyde in $0.1 \mathrm{M}$ phosphate buffered saline (PBS). The brains were removed and stored overnight at $4{ }^{\circ} \mathrm{C}$ in $4 \%$ paraformaldehyde in $0.1 \mathrm{M}$ PBS. The next day the brains were transferred into a $30 \%$ sucrose solution, in which they remained until they had sunk (this took 4 to 5 days). Coronal sections of 40 $\mu \mathrm{m}$ were made with a freezing microtome and slices containing a piece of the lesion were stained with cresyl violet. The site of the lesion was recognizable as a blue dot, which enabled a microscopic localization of the electrode tip.

\section{RESULTS}

\section{Electrode placements}

Six of the 13 rats were excluded from data analysis, either because of incorrect electrode placement, or of a disproportionate high level of EEG artefacts. The electrode aimed at the LA was located in or slightly dorsal to the LA in four of the remaining seven rats. In the remaining three rats, the electrode was positioned somewhat medial or dorsal to the LA, but within $0.6 \mathrm{~mm}$ of its anatomical boundaries.

\section{Conditioning}

Figure 1 depicts the discrimination performance of the two groups across the three conditioning sessions. The repeated-measures ANOVA on the freezing times from the seven rats included in the analysis ( $\underline{n}=3$ for Group 1 and $\underline{n}=$ 4 for Group 2) revealed a main effect of CS type $\left(\mathrm{F}_{1,6}=17.49, \mathrm{p}<.01\right)$, reflecting overall more freezing to $\mathrm{CS}^{+}$than to $\mathrm{CS}^{-}$. However, the interaction between CS type and Group was also significant $\left(\mathrm{F}_{1,6}=13.93, \mathrm{p}<.05\right)$, reflecting the fact that the rats in Group 1 froze significantly longer in response to the $\mathrm{CS}^{+}$(mean: $3.9 \pm .2 \mathrm{~s}$ ) than they did to the $\mathrm{CS}^{-}$(mean: $2.3 \pm .2 \mathrm{~s} ; \mathrm{F}_{1,2}=$ $42.32, p<.05$ ), whereas there was no significant difference in the corresponding freezing times (means $2.9 \pm .3 \mathrm{~s}$ and $2.8 \pm .3 \mathrm{~s}$, respectively) for the rats in Group $2\left(\mathrm{~F}_{1,3}=.10, p>.05\right)$. This pattern of results is identical to that performed on the behavioral data of all 13 subjects. 

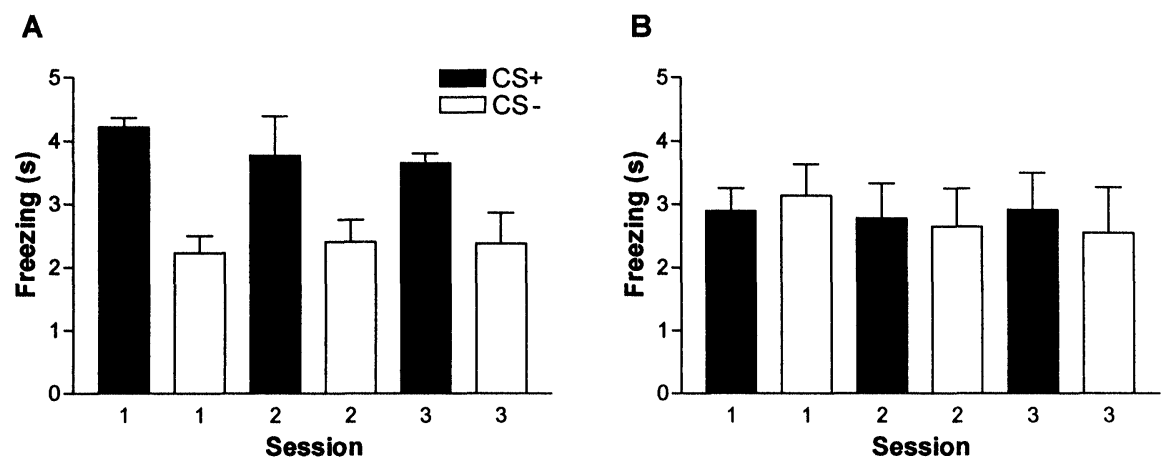

Fig. 1: Groups' mean time spent freezing in response to the $\mathrm{CS}^{+}$and the $\mathrm{CS}^{-}$in each conditioning session. (A) Data of Group $1(\underline{n}=3)$. (B) Data of Group $2(\underline{n}=4)$. Error bars correspond to standard errors of the mean.

\section{Evoked potentials}

The acoustic frequency of the CS had a striking effect on the amplitude of EPs. The 10$\mathrm{kHz}$ tone elicited EPs of considerably larger amplitude than did the $6-\mathrm{kHz}$ tone. The impact of acoustic frequency can easily be appreciated in Fig. 2, in which the pre-conditioning EPs (averaged across the two groups) are depicted for each acoustic frequency. Repeated measures ANOVAs, with acoustic frequency as factor on the data, revealed a significant effect of acoustic frequency for all components, with the $10-\mathrm{kHz}$ tone eliciting a larger amplitude than did the $6-\mathrm{kHz}$ tone. The statistics for components N24, P38, N57 and P82 are $F_{1,6}=13.97, \underline{p}=.01 ; F_{1,6}=19.46, \underline{p}<.01 ; F_{1,6}$ $=14.02, \underline{p}=.01 ; \mathrm{F}_{1,6}=8.20, \underline{\mathrm{p}}<.05$, respectively.

A late, slow, and large negative component was present in the EPs from the LA after conditioning. In each subject, this component was present in EPs to the $\mathrm{CS}^{+}$and the $\mathrm{CS}^{-}$and was also present before conditioning, albeit generally at smaller amplitudes. This component started at about $80 \mathrm{~ms}$ and ended around $300 \mathrm{~ms}$, reaching its peak around $150 \mathrm{~ms}$ and was, therefore, labeled N150. Pre- and post- conditioning EEGs were divided into 4 blocks of 50 $\mathrm{CS}^{+} / \mathrm{CS}^{-}$presentations and the EPs were made per block. A Group $\times$ CS Type $\times$ Block ANOVA on the amplitude of the $\mathrm{N} 150$ as observed in Blocks 1 and 4 of the pre-conditioning phase, revealed a significant main effect of block $\left(\mathrm{F}_{1,5}=12.69, p<.05\right)$,

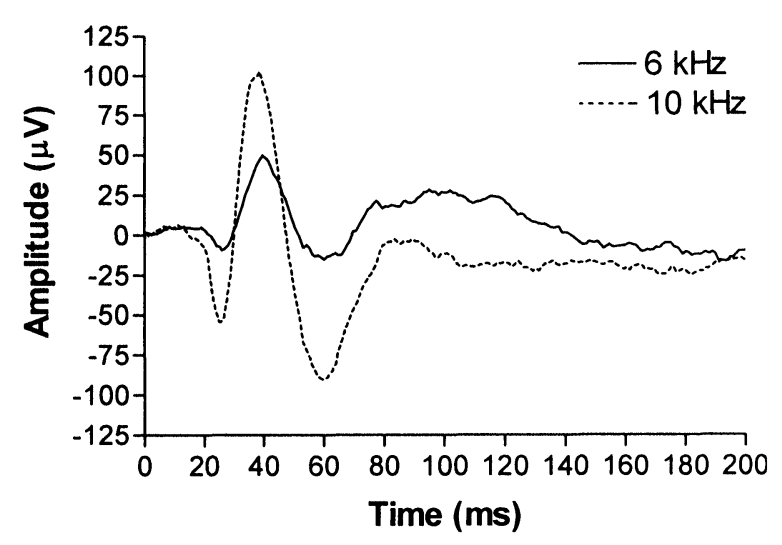

Fig. 2: Pre-conditioning EPs from the amygdala for the $6-$ and $10-\mathrm{kHz}$ tones $(\underline{\mathrm{n}}=7)$. 
reflecting a decrease in $\mathrm{N} 150$ amplitude from Block 1 (mean amplitude: $-71.2 \mu \mathrm{V}$ ) to Block 4 (mean: $-28.9 \mu \mathrm{V})$. The Group $\times$ CS Type interaction was also significant $\left(\mathrm{F}_{1,5}=6.86, p<.05\right)$, but subsequent simple main effect analyses failed to detect significant differences between and within groups (all ps $>.1$ ). All remaining main and interaction effects were also not significant $(\underline{F} s<1)$.

\section{A}

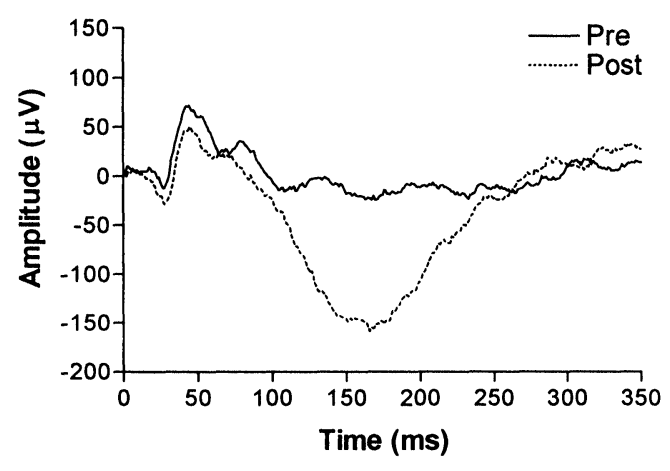

C

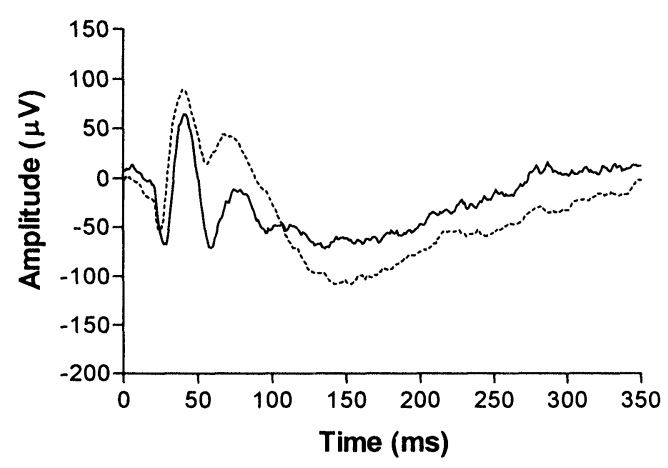

The N150 peak amplitudes of Block 1 of the pre-conditioning phase were compared with the amplitudes of Block 1 of the post-conditioning phase using a Group $\times$ CS Type $\times$ Phase repeated measures ANOVA. This analysis revealed a main effect of Phase $\left(F_{1,6}=48.73, \underline{p}=.001\right)$, reflecting larger post-conditioning than pre-conditioning amplitudes (see Fig. 3).

\section{B}

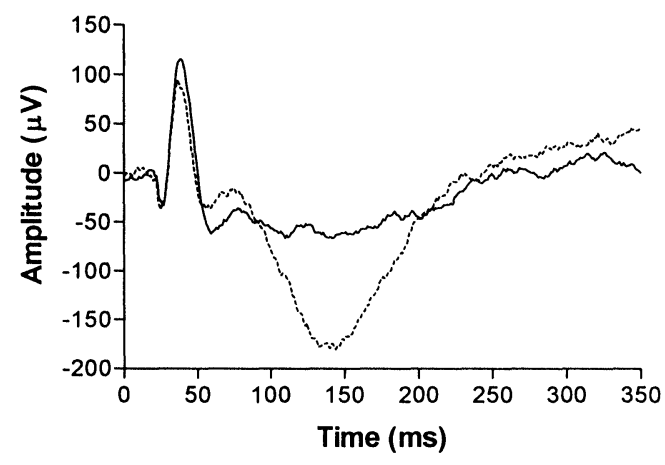

D

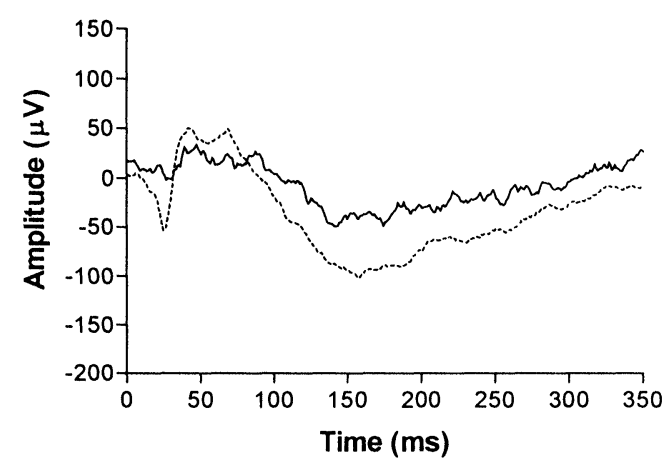

Fig. 3: Pre- and post-conditioning EPs from the amygdala as evoked by the $\mathrm{CS}^{+}$and $\mathrm{CS}^{-}$in the first 50 -trial block of each phase. (A) and (B) depict, respectively, the $\mathrm{CS}^{+}-$and $\mathrm{CS}^{-}-\mathrm{EPs}$ of Group $1(\underline{\mathrm{n}}=3)$. (C) and (D) depict, respectively, the $\mathrm{CS}^{+}$- and $\mathrm{CS}^{-}$-EPs of Group $2(\underline{n}=4)$. 
The analysis also detected a significant interaction between phase and group, reflecting a main effect of Phase in Group $1\left(\mathrm{~F}_{1,2}=112.89, \mathrm{p}<.01\right)$, but not in Group $2\left(\mathrm{~F}_{1,3}=4.24, \mathrm{p}>.1\right)$. All other main and interaction effects were not significant (ps $>$.08). An ANOVA comparing Block 4 of the preconditioning phase with Block 1 of the postconditioning phase again revealed a main effect of Phase $\left(\mathrm{F}_{1,5}=492.62, \mathrm{p}<.001\right)$, which was also found with a separate ANOVA for Group $1\left(\mathrm{~F}_{1,2}=\right.$ $332.09, p<.01)$ and Group $2\left(\mathrm{~F}_{1,3}=141.38, \mathrm{p}<.01\right)$.

Figure 4 shows the EPs of each 50 -trial block of the post-conditioning phase. A Group $\times$ CS Type $\times$ Block ANOVA on the N150 peak amplitudes revealed only a main effect of Block $(F 3,15=24.9$, $\mathrm{p}<.01$; other ps $>.09$ ).

\section{A}

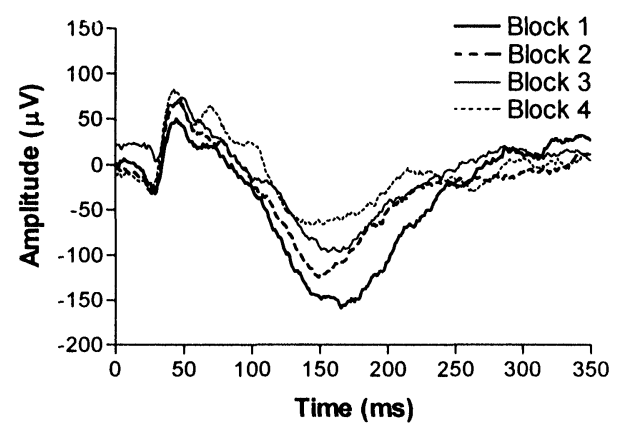

C

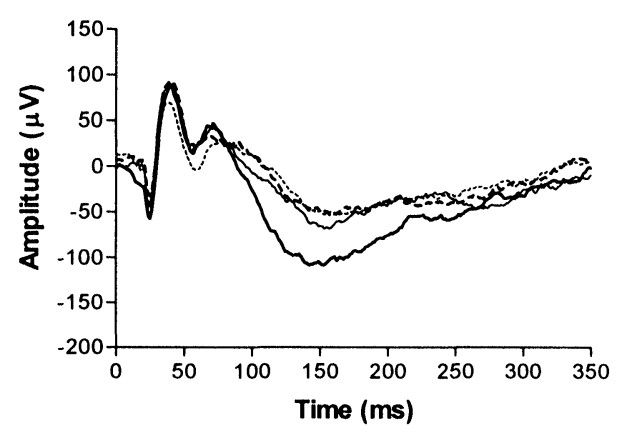

Subsequent tests of within-subjects contrasts revealed a significant difference between Block 1 and later blocks $(\mathrm{F} 1,5=64.6, \mathrm{p}<.01)$, reflecting the decrease in amplitude across non-reinforced CS presentations, which was most marked from Block 1 to Block 2.

\section{DISCUSSION}

\section{Nature of the N150}

The major finding of this study is the enhancement of a large late component (the N150) in response to both the $\mathrm{CS}^{+}$and the $\mathrm{CS}^{-}$after differential fear conditioning in all subjects. An

\section{B}

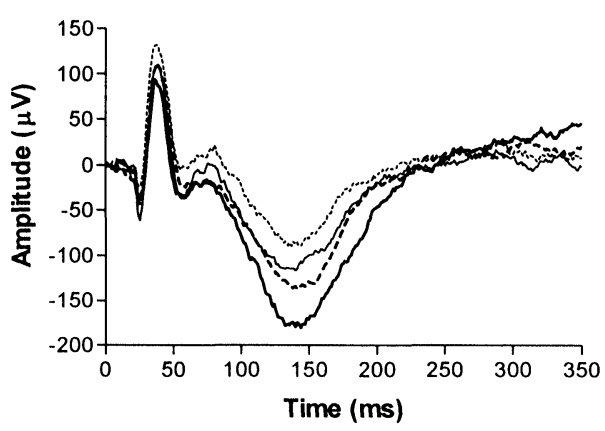

D

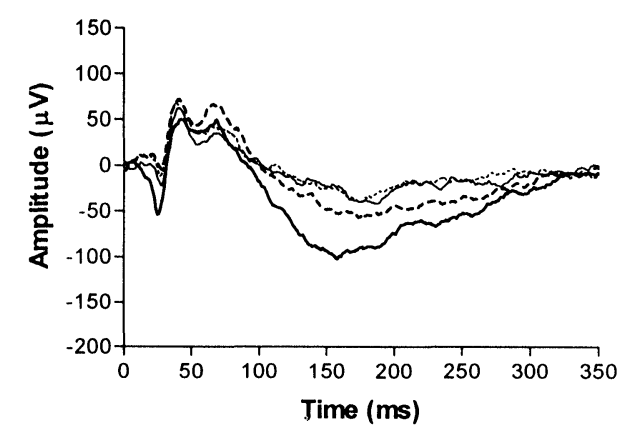

Fig. 4: Post-conditioning $\mathrm{CS}^{+}$- and $\mathrm{CS}^{-}$-EPs from the amygdala in 50-trial blocks. (A) and (B) depict, respectively, the $\mathrm{CS}^{+}$- and CS-EPs of Group $1(\underline{n}=3)$. (C) and (D) depict, respectively, the $\mathrm{CS}^{+}$- and $\mathrm{CS}^{-}$-EPs of Group $2(\underline{n}=4)$. 
important question is what does this component reflect? Some hints as to its meaning come from studies performed by Collins and Paré (2000), who found a similar late component in field potentials recorded in the cat LA. Collins and Paré also found a late negative wave having peak latency comparable to the $150 \mathrm{~ms}$ observed in the present study, after differential fear conditioning in EPs to the $\mathrm{CS}^{+}$. Although this component was also present in EPs to the $\mathrm{CS}^{-}$, it was enhanced substantially only in $\mathrm{CS}^{+}$-EPs and only after conditioning. In another study (Paré \& Collins, 2000), the anticipation of a shock was induced by presenting series of six tones, interrupted by a brief period of silence between the fourth and fifth tone, followed immediately by a foot shock. Physiological measurements indicated that the cats anticipated the shock during the silent period and that anticipation was maximal during the last two tones. Evoked potentials to each of the six tones contained a late N150-like component, with the amplitude being increased substantially during the last tone before the shock.

The results obtained by Collins and Paré, and our own results, suggest that the observed late component is susceptible to the anticipation of an aversive event, such as an electric shock. Both their and our data show that the amplitude of this late component increases when a tone-shock association is formed and decreases when this association is extinguished. These findings give way to an interpretation of the N150 in terms of the anticipation of the electric shock. The late component observed in the present study, however, was also present in the pre-conditioning phase, at least initially, and decreased across pre-conditioning trials.

Moreover, in their anticipatory fear study, Paré and Collins (2000) also detected this component in a control condition receiving a tone-series that was never followed by a shock. What the $\mathrm{N} 150$ reflects in these cases remains to be determined. But nevertheless, we did observe a significant enhancement of N150 after conditioning, which is in accordance with the claim that this component is related to US anticipation.

In the present study, a N150 was also present in EPs of the $\mathrm{CS}^{-}$, which seems to be at odds with an anticipation hypothesis because this stimulus was not followed by shock. Nevertheless, this result could be explained by the phenomenon of stimulus generalization: The rats responded to the $\mathrm{CS}^{+}$and to the $\mathrm{CS}^{-}$, implying the presence of at least some anticipation of shock after the latter stimulus. The relatively high conditioned freezing in response to the $\mathrm{CS}^{-}$in both groups supports this interpretation. Group 2 even completely failed to show differential freezing to the two types of CS.

The present study used a reinstatement procedure in the post-conditioning phase, with the aim of preventing extinction of previously formed associations. As the N150 decreased in the course of the post-conditioning phase, we must conclude that extinction did occur, at least electrophysiologically, despite such manipulation. Apparently, extinction was so strong that it could not be counteracted by occasional reinstatement trials.

A direct neuronal index of the anticipation of an aversive stimulus was obtained by Quirk et al. (1997). In this study, CS-elicited single-cell activity was recorded in areas of the auditory cortex that project to the LA. After fear conditioning (namely, during extinction trials), cortical unit activity as a response to the CS increased progressively from $800 \mathrm{~ms}$ before the time that the US had been presented during conditioning until exactly the time corresponding with the US presentation time during conditioning. This late response can therefore be interpreted as reflecting US anticipation. Interestingly, this response disappeared completely after bilateral lesions of the amygdala (Armony et al., 1998). Whether and how these findings relate to the present study must be established. 


\section{Origin of the N150}

In this, and several other studies (Collins \& Paré, 2000; Kuniecki et al., 2002; Paré \& Collins, 2000), a late EP component was recorded in the amygdala. Studies simultaneously recording singlecell activity and EPs using the same electrode have demonstrated that early negative and positive EP components correspond with respective increases and decreases in LA unit activity (Collins \& Paré, 1999, 2000; Rogan \& LeDoux, 1995). In contrast, the late negative component of interest here is accompanied by only a modest increase in LA unit firing (D. Paré, personal communication, 2002). Therefore, it seems unlikely that LA firing activity alone can account for the late component found in amygdala recordings. In the present study, EPs were recorded simultaneously in the auditory cortex. In these EPs, both to the $\mathrm{CS}^{+}$and $\mathrm{CS}^{-}$, a late negative component was also present after fear conditioning. Compared with the amygdaloid component, this cortical component started earlier, but reached its peak amplitude at a similar latency. This suggests a cortical source of, or contribution to, the late component registered in amygdala EPs. Future studies should clarify the possible involvement of the (auditory) cortex, for example, by means of cortical single-cell recordings, perhaps combined with lesions of the amygdala. At present though, the neural generator of the N150 cannot be identified with certainty.

\section{Early EP components}

The first negative component of EPs from the amygdala had an average latency of $24 \mathrm{~ms}$. This time is close to the average latency of $25 \mathrm{~ms}$ reported by Quirk et al. (1995) for the responses of individual LA neurons to auditory stimulation in the pre-conditioning phase. In mice, Tang et al. (2001) found a negative CS-EP component with a mean peak latency of $24.5 \mathrm{~ms}$, which increased as a result of fear conditioning. Other studies have reported a latency of $18.5 \mathrm{~ms}$ for the first negative wave of field potentials recorded in the lateral nucleus of the rat (Rogan et al., 1997; Rogan \& LeDoux, 1995). Despite the longer latency of the early component found in the present study in comparison with the latter studies, the polarity of the waves and the general architecture of the EPs did not differ from the auditory EPs found by Rogan et al. and by Collins and Paré (2000). Therefore, we can assume that this component reflects local amygdaloid unit activity and that fear conditioning should enhance its amplitude. However, such an enhancement was not found, which may be due to the low number of animals on which the analysis was based and on the learning deficit observed for the rats in group 2 .

\section{Effects of acoustic frequency}

A robust finding was that the $10-\mathrm{kHz}$ tone elicited EPs of considerably larger amplitude than did the 6-kHz tone. Bordi et al. (1993) examined the response magnitude of individual LA neurons to tones of different acoustic frequencies in the rat. So-called frequency-modulated (FM) tones were used: tones with a certain centre acoustic frequency and a range of $\pm 2.5 \mathrm{kHz}$. FM tones with a center frequency of $5 \mathrm{kHz}$ elicited weak responses from LA neurons, whereas $10-\mathrm{kHz}$ FM tones elicited strong responses. This result may explain the observed difference in amplitude between EPs to the 6- and $10-\mathrm{kHz}$ CSs. However, Collins and Paré (2000) reported that in the LA of the cat, $10-\mathrm{kHz}$ tones resulted in smaller EPs than did $5-\mathrm{kHz}$ tones.

\section{Polarity of the N150}

Recently, Kuniecki et al. (2002) also found a late component in the amygdala after differential 
fear conditioning in the rat. This component had a positive voltage and correlated with $\mathrm{CS}^{+}$-elicited decelerations in heart rate. The latency is comparable to the latency in the present study and in other studies (Collins \& Paré, 2000; Paré \& Collins, 2000). It seems likely that the same component was registered in all these studies, but that its polarity is sometimes inverted, perhaps depending on the specific recording techniques (e.g., monopolar vs. bipolar, location of reference electrode). Future studies should address this issue.

\section{CONCLUSION}

In conclusion, a large late component was present after fear conditioning in CS-evoked EPs from the rat's amygdala and auditory cortex. The data presented here add to previous data suggesting that this component, at least in part, reflects the anticipation of a biologically significant event, as induced in conditioning procedures.

\section{REFERENCES}

Armony JL, Quirk GJ, LeDoux JE. Differential effects of amygdala lesions on early and late plastic components of auditory cortex spike trains during fear conditioning. J Neurosci 1998; 18: 25922601.

Blair HT, Schafe GE, Bauer EP, Rodrigues SM, LeDoux JE. Synaptic plasticity in the lateral amygdala: A cellular hypothesis of fear conditioning. Learn Memory 2001; 8: 229-242.

Bordi F, LeDoux J, Clugnet MC, Pavlides C. Singleunit activity in the lateral nucleus of the amygdala and overlying areas of the striatum in freely behaving rats: Rates, discharge patterns, and responses to acoustic stimuli. Behav Neurosci 1993; 107: 757-769.

Bouton ME, Bolles RC. Role of conditioned contextual stimuli in the reinstatement of extinguished fear. J Exp Psychol Anim B 1979; 5: 368-378.

Collins DR, Paré D. Reciprocal changes in the firing probability of lateral and central medial amygdala neurons. J Neurosci 1999; 19: 836-844.

Collins DR, Paré D. Differential fear conditioning induces reciprocal changes in the sensory responses of lateral amygdala neurons to the $\mathrm{CS}^{+}$and the $\mathrm{CS}^{-}$. Learn Memory 2000; 7: 97-103.

Fanselow MS. The adaptive function of conditioned defensive behavior: An ecological approach to Pavlovian stimulus substitution theory. In: Blanchard RJ, Brain PF, Blanchard DC, Parmigiani S, eds, Ethoexperimental Approaches to the Study of Behavior. Dordrecht, The Netherlands: Kluwer, 1989, 151-166.

Hennevin E, Maho C, Hars B. Neuronal plasticity induced by fear conditioning is expressed during paradoxical sleep: Evidence from simultaneous recordings in the lateral amygdala and the medial geniculate in rats. Behav Neurosci 1998; 112: 839-862.

Kuniecki M, Coenen AML, Kaiser J. Correlation between long latency evoked potentials from amygdala and evoked cardiac response to fear conditioned stimulus in rats. Acta Neurobiol Exp 2002; 62: 85-92.

LeDoux JE. Emotion: Clues from the brain. Annu Rev Psychol 1995; 46: 209-235.

LeDoux JE. Emotion circuits in the brain. Annu Rev Neurosci 2000; 23: 155-184.

LeDoux JE, Farb CR, Romanski LM. Overlapping projections to the amygdala and striatum from auditory processing areas of the thalamus and cortex. Neurosci Lett 1991; 134: 139-144.

Maes JHR, Vossen JMH. Competition between contextual and punctate stimuli for inhibitory control in a Pavlovian discrimination procedure. Learn Motiv 1993; 24: 194-218.

Maren S. Auditory fear conditioning increases $\mathrm{CS}^{-}$ elicited spike firing in lateral amygdala neurons even after extensive overtraining. Eur J Neurosci 2000; 12: 4047-4054.

Maren S. Neurobiology of Pavlovian fear conditioning. Annu Rev Neurosci 2001; 24: 897-931.

Meeren HKM, Van Cappellen van Walsum AM, Van Luijtelaar ELJM, Coenen AML. Auditory evoked potentials from auditory cortex, medial geniculate nucleus, and inferior colliculus during sleep-wake states and spike-wave discharges in the WAG/Rij rat. Brain Res 2001; 898: 321-331.

Paré D, Collins DR. Neuronal correlates of fear in the lateral amygdala: Multiple extracellular recordings 
in conscious cats. J Neurosci 2000; 20: 2701-2710.

Paxinos G, Watson $\mathrm{C}$. The rat brain in stereotaxic coordinates, $4^{\text {th }}$ ed. San Diego, California, USA: Academic Press, 1998.

Quirk GJ, Armony JL, LeDoux JE. Fear conditioning enhances different temporal components of toneevoked spike trains in auditory cortex and lateral amygdala. Neuron 1997; 19: 613-624.

Quirk GJ, Repa JC, LeDoux JE. Fear conditioning enhances short-latency auditory responses of lateral amygdala neurons: Parallel recordings in the freely behaving rat. Neuron 1995 ; 15 : 1029 1039.

Rogan MT, LeDoux JE. LTP is accompanied by commensurate enhancement of auditory-evoked responses in a fear conditioning circuit. Neuron 1995; 15: 127-136.

Rogan MT, Stäubli UV, LeDoux JE. Fear conditioning induces associative long-term potentiation in the amygdala. Nature 1997; 390: 604-607.

Tang J, Wotjak CT, Wagner S, Williams G, Schachner M, Dityatev A. Potentiated amygdaloid auditoryevoked potentials and freezing behavior after fear conditioning in mice. Brain Res 2001; 919: 232-241.

Veening JG, Swanson LW, Sawchenko PE. 1984. The organization of projections from the central nucleus of the amygdala to brainstem sites involved in central autonomic regulation: A combined retrograde transport-immunohistochemical study. Brain Res 303: 337-357. 

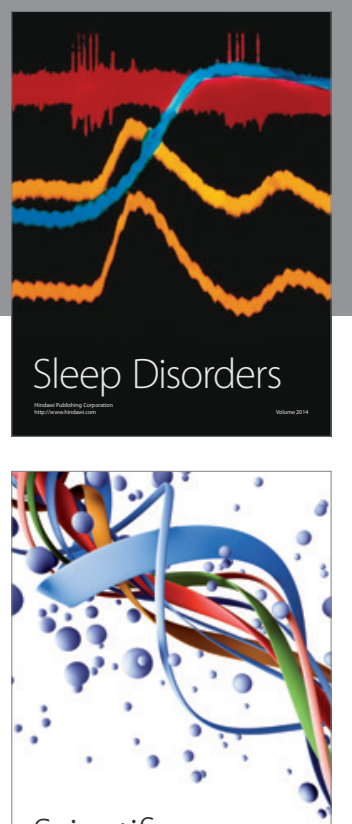

Scientifica
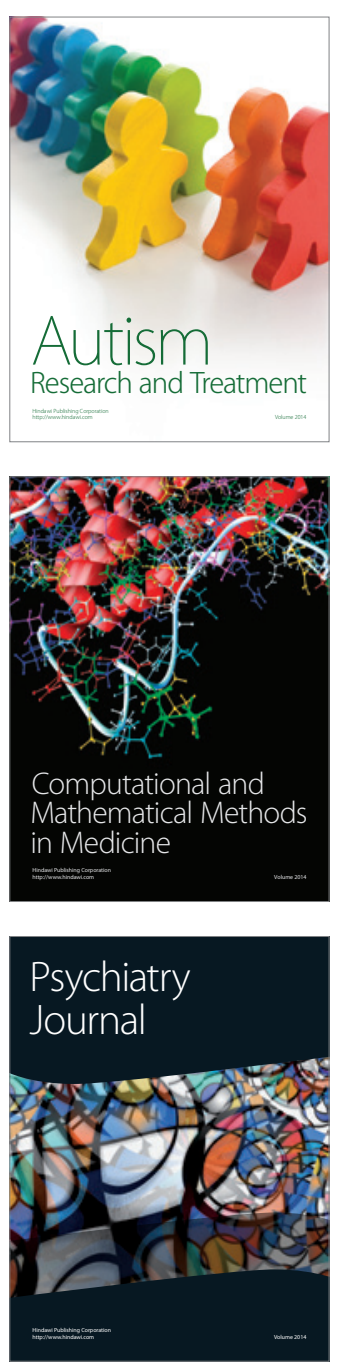
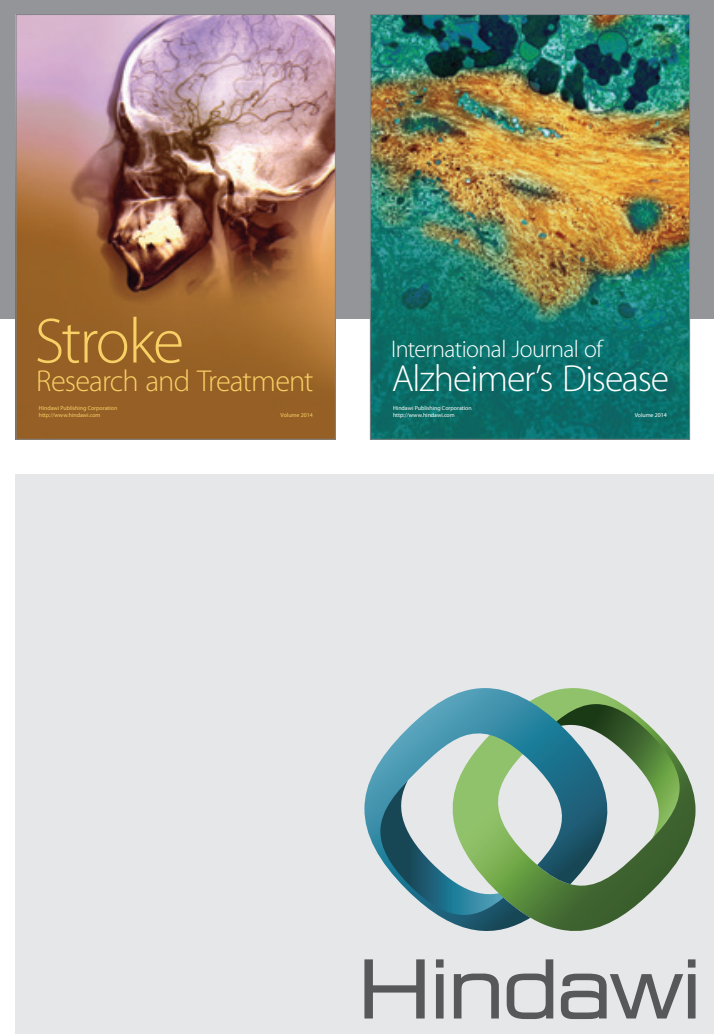

Submit your manuscripts at

http://www.hindawi.com
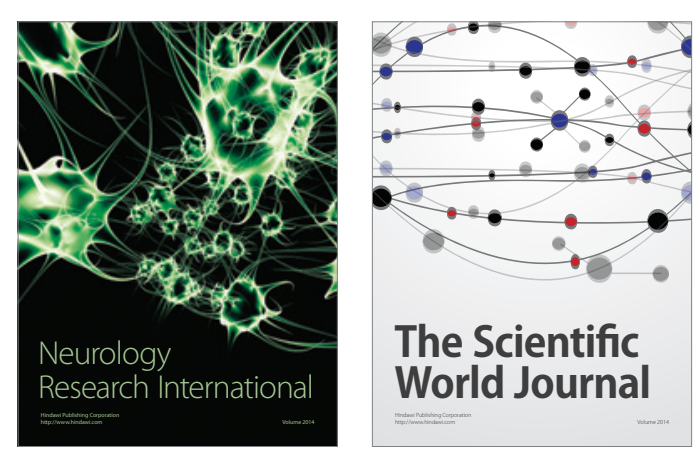

The Scientific World Journal

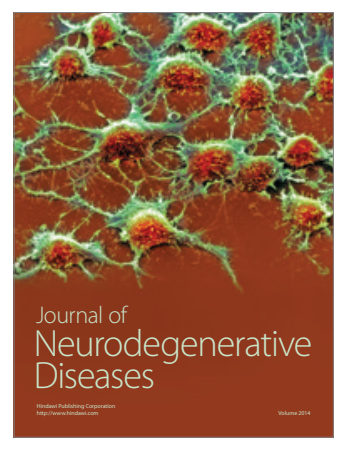

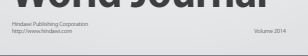

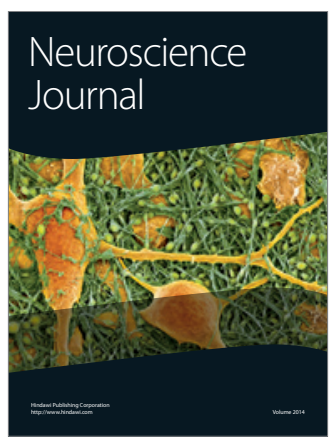

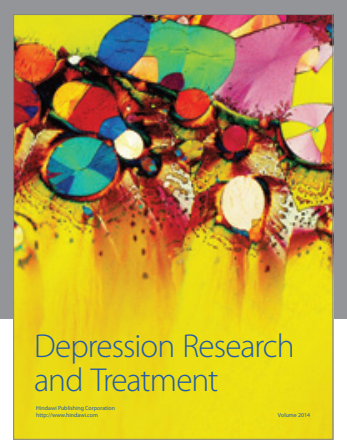
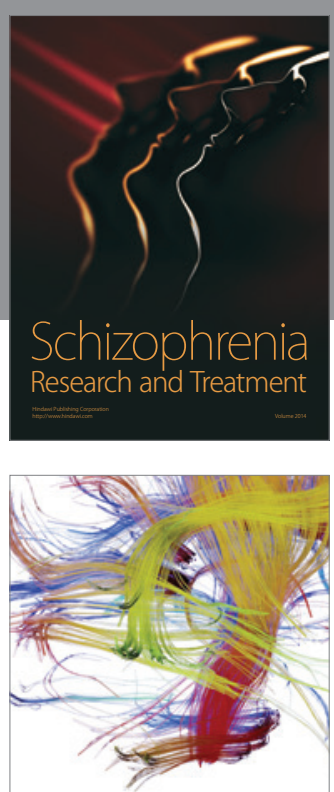

Brain Science

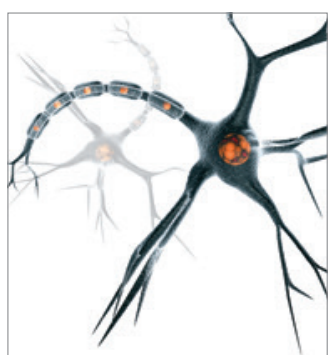

Neural Plasticity
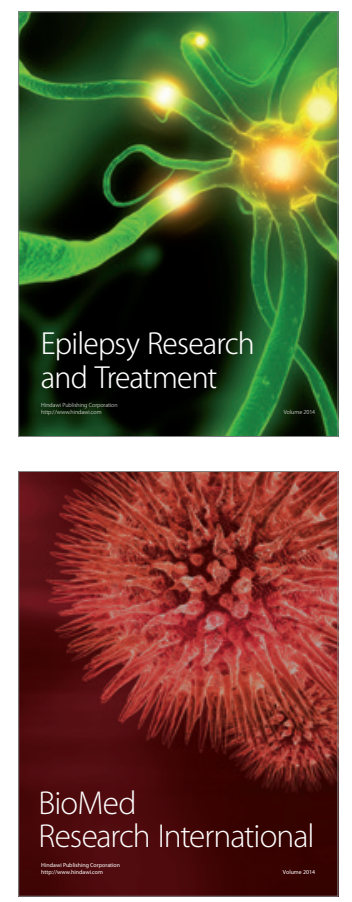

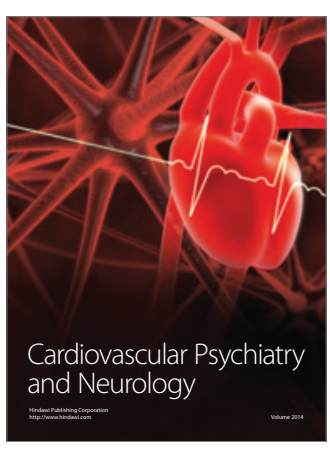

Parkinson's

Disease
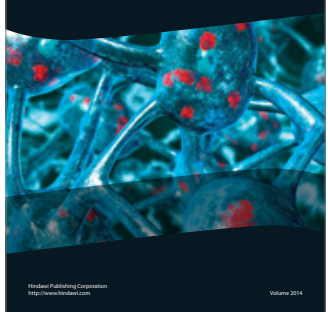